Brewin, C. R., Wing J. K., Mangan, S. P. et al (1987) Principles and practice of measuring needs in the longterm mentally ill. Psychological Medicine, 17, 971-981.

Donabedian, A. (1980) The Definition of Quality and Approaches to its Assessment. Ann Arbor: Michigan Health Administration Press.

JENKINS, R. (1990) Towards a system of outcome indicators for mental health care. British Journal of Psychiatry, 157, 500-514.

MAXWELL, R. (1984) Quality assessment in health. British Medical Journal, 288, 1470-1472.

OVRetVEIT, J. (1990) Quality Health Services. London: Brunel Institute of Organisation and Social Studies.
PETERs, T. (1987) Thriving on Chaos - a handbook for a management revolution. London: Pan Books.

Shaw, C. D. (1990) Criteria based audit. British Medical Journal, 300, 649-651.

StePHENS, G. \& BenNetT, J. (1989) Clinical auditoccurrance screening for quality assurance. Health Services Management, 85, 178-181.

WiLson, C. R. M. (1989) Hospital-wide Quality Assurance. Canada: W. B. Saunders.

A full list of references is available from the author on request.

\title{
Do GPs want community mental health facilities?
}

\author{
IAN Hughes, Principal Psychologist, Whitchurch Hospital, Park Road, Whitchurch, \\ Cardiff CF4 7XB; RoBERT KIDD, Research Assistant; RALPH CANTOR, General \\ Practitioner; and STEPHEN KIllick, Assistant Psychologist, Cardiff, South \\ Glamorgan
}

Much of a typical general practitioner's time is spent dealing with people who present with "psychological" problems. Of those people who are detected as suffering from a mental health problem, most are then dealt with by the GP without recourse to specialist services. There is a wide variation in referral rate, and a recent review (Wilkinson, 1989) suggests that GPs are most likely to refer a patient to a psychiatrist when he/she has failed to respond to previous GP treatment, an opinion about diagnosis is sought, or there is some specific request either by the patient or another person involved. One of the reasons why GPs are disinclined to refer is their perception of stigma associated with attending a psychiatric clinic, although they do not appear to be unduly perturbed by aspects of the referral process itself, such as a waiting list. Overall, it appears that around $95 \%$ of patients in general practice presenting with mental distress are not referred to a psychiatrist. As well as being concerned about the stigma associated with traditional psychiatric services, we hypothesise that another concern of GPs may be a lack of liaison and consultation between primary and secondary care services.

There are, perhaps, three possible ways in which GPs and mental health specialists may collaborate: these can be described as the "increased output" model, the "replacement" model, and the "liaisonattachment" model. The increased output model is closest to the traditional service with GPs being encouraged to refer more patients to hospital-based facilities. The replacement model involves major structural change, based on the principle of a community approach to mental health problems with a multi-disciplinary community mental health team which is separate from the "parent" psychiatric hospital. This model envisages the replacement of the GP as a primary provider of mental health care by a community mental health team. The liaisonattachment model involves movement of mental health specialists out of the hospital into general practice settings. This is not simply a change of venue for the out-patient clinics. If properly adopted, it necessitates a real change of working practice for those concerned (Creed \& Marks, 1989).

\section{The study}

We undertook to investigate GPs' views on services for people with mental health problems. Our interview study involved a sector of Cardiff which has a population of around 100,000 and a variety of types 
of neighbourhood, including relatively affluent suburbs, peripheral estates and older areas showing features typical of inner cities. In line with the Welsh Office's Mental Illness Strategy (Welsh Office, 1989), a multidisciplinary community mental health team will soon be operating out of an easily accessible city centre location. This will be in contrast with the existing service, a fairly traditional one, based around the old county psychiatric asylum and a newer DGH units. Two of the larger GP practices already have sessional inputs from psychologists on their own premises.

We prepared a list of 55 GPs active in south-east Cardiff. Constraints upon time prevented face-toface interviews being undertaken with all the GPs, so 32 were selected at random. Only one GP refused to participate. A content analysis was subsequently performed upon the transcribed interviews by a researcher not involved in the data collection.

Participating GPs were given a brief outline of a proposed Community Mental Health Centre (CMHC) to be sited in the sector. The outline emphasised that a multidisciplinary team would be providing assessment and that there would be a "rapid response" service; this is not intended to be an open-door/walk-in service but initial assessment would be guaranteed within 24 hours of the centre being contacted. Here we describe in detail the GPs' views on the provision of the mental health services.

\section{Findings}

So few GPs spontaneously commented on positive aspects of the present service that these data were not analysed. There were more reports on negative aspects of the service: inadequate community support was mentioned by six, but lengthy waiting lists and stigma only by four. Concerning possible general improvements to the service, eight suggested that having clinical psychologists based in surgeries would be desirable, followed by the establishment of a multi-professional community health team (seven).

Those interviewed were asked their views on having such a community mental health team in the area: all but one GP indicated that they supported the idea. Seven respondents believed that such a team might lead to better communication. Comments were requested on the three possible models outlined above. The increased output model (i.e. involving a better-resourced version of the existing service) was viewed the least favourably: only four GPs indicated that they approved of it, and only three considered it the best option. The replacement model, with the CMHC becoming the supplier of primary mental health care, was approved by 12 respondents and nine thought it the best, but nine were concerned that the service would be impossibly overloaded. The liaison- attachment model, with members of a specialist mental health service based at primary care facilities, was very popular, with 19 indicating that this was their favoured option.

If, as had been described at the outset of the interview, a CMHC service were to be provided, one consequence could be that GPs would no longer be able to refer their patients to a nominated psychiatrist working in another geographical sector of Cardiff - but with whom they might have developed a close working relationship. Respondents were divided as to whether this was acceptable, with 16 stating that this would not bother them, but 15 saying that they would feel restricted in their options for treatment. However, fewer doctors were disturbed by the idea of referring to a team rather than to a named individual psychiatrist: only two GPs indicated that they would much prefer the patient to see a psychiatrist first while 26 suggested that this change of practice would not particularly cause them concern. Almost four-fifths of respondents (24) indicated that they considered the proposed rapid response service to be a very useful development. When asked what sort of help they would appreciate from a CMHC, 17 expressed a desire for training from the team, 16 hoped for increased communication and liaison, and 12 desired joint sessions with team members in their surgery.

\section{Conclusions}

These GPs do not appear conservative in their ideas for the future, with there being enthusiasm for a CMHC approach, although anxiety about overloading the service was also expressed. Non-statutory agencies were already well used, but a surprising lack of knowledge about non-medical specialists other than the GPs showed clinical psychologists (e.g. community OTs) to whom patients could have been referred.

The GPs appeared willing to take responsibility for managing patients who presented with serious mental illness. In some ways this may be laudable, but it could conflict with, say, rehabilitation specialists based at the CMHC who might see themselves as the main focus of care for such people. Although there was support for the CMHC approach, it is clear that a majority of the GPs would have preferred a rather different approach, the liaison-attachment model. It is perhaps understandable that family doctors might not be enthusiastic about a radically different community mental health service which could by-pass their role as the co-ordinator of health care for a patient. This bears out the recent study by Brown \& Tower (1990) who found that the most popular link for GPs and psychiatrists was a form of liaison in which the two undertook joint assessments. One of the main rationales for the community mental health 
centre approach is that this enhances accessibility for clients, as has been demonstrated, for example, in Torbay (Whittle \& Logan, 1990). However, this very accessibility might pose difficulties for co-ordination with the GP, and could prove particularly problematic for any budget-holding practices. The liaisonattachment approach on the other hand much more clearly enhances the services provided within the general practice setting and allows the GP to remain the focal point of the service being delivered. Sessional input from specialists would also be easier to incorporate into practice budgets under this model.

One has to caution that the present study was small-scale, involved content analysis of a semistructured interview and may have been affected by certain demand characteristics. (For instance, some interviewees would have been aware that the research was being conducted under the auspices of the local Clinical Psychology Department.) Some GPs may also have realised that a CMHC approach is very much the received wisdom promulgated by the Welsh Office. However, few local GPs would have had first-hand experience of a totally nonhospital-based mental health service, and one might have expected this to push them towards conservatism. The lesser degree of enthusiasm for the CMHC approach compared with the not-to-be-adopted liaison-attachment approach should, however, be taken seriously as an indicator of general prac- titioners' preferences. It remains to be seen whether this relative lack of enthusiasm for the former approach will seriously jeopardise its success.

\section{Acknowledgements}

The authors gratefully acknowledge the assistance of Dr R. Thomas and Mr S. Rollnick in designing the study, and of the general practitioners who participated in it.

Financial support was received from the Welsh Scheme for the Development of Health and Social Research.

\section{References}

Brown, L. M. \& TOWER, J. E. C. (1990) Psychiatrists in primary care: would general practitioners welcome them? British Journal of General Practice, 40, 369-371.

CREED, F. \& MARKS, B. (1989) Liaison psychiatry in general practice: a comparison of the liaison attachment scheme and shifted outpatient clinic models. Journal of the Royal College of General Practitioners, 39, 514-517.

Welsh OfFiCE (1989) Mental Illness Services: a Strategy for Wales.

Whittle, P. \& Logan, V. (1990) Accessibility to a community mental health centre. Clinical Psychology Forum, December 1990, 15-19.

WILKINSON, G. (1989) Referrals from general practitioners to psychiatrists and paramedical mental health professionals. British Journal of Psychiatry, 154, 72-76. 